\title{
PLANTAÇÃO DE EUCALIPTOS: UMA ALTERNATIVA ECONÔMICA OU UM PROBLEMA AMBIENTAL?
}

\author{
Kerli Paula Viebrantz \\ Mestre em Ciências Ambientais
}

\begin{abstract}
Resumo
A colonização do Município de Mondaí, contava com agricultores que migraram em busca de terras, como estratégia de reprodução social camponesa. Os depoimentos e documentos apontam que houve práticas de devastação das florestas em detrimento do meio ambiente. Contemporaneamente observase o contrário, um reflorestamento intenso, atingindo diversas linhas rurais. Trata-se, no entanto, de estratégia de empresários e profissionais liberais em plantar eucalipto como estratégia de reprodução social, à medida que a madeira possa servir como forma de poupança e renda ao investidor.
\end{abstract}

Palavras-chave: colonização, deflorestamento, extensão rural, plantio de eucaliptos. 


\section{O processo de Colonização e Organização do Ambiente}

O processo de colonização e organização do espaço do oeste catarinense se dá a partir dos anos de 1920. A paisagem florestal transforma-se em lavouras, introduzidas pelos colonos, ou seja, um campesinato de descendentes de europeus. A exploração da pequena propriedade, em regime de trabalho familiar, o modo de vida, sofre poucas alterações nas décadas seguintes. A partir dos anos sessenta, com a introdução de novas técnicas e tecnologias de cultivo, passa a haver uma aceleração nas mudanças.

A região da mata passou a ser explorada a partir de 1917 com a chegada das empresas colonizadoras. Acreditava-se que para incorporar a terra contestada à Santa Catarina, ocupar o "vazio demográfico" e aumentar a produção agrícola era necessário a colonização por descendentes de europeus, pois os mesmos seriam os "construtores do progresso e da civilização" (RENK, 2000, FLORES e SERPA, 2005). O imaginário social considerava também que a colonização era necessária para reafirmar os limites da região. $\mathrm{O}$ governo catarinense pretendia também ocupar o "deserto" ao norte do Rio Grande do Sul e provar que essas terras eram brasileiras e catarinenses, bem como enfraquecer grupos conflitantes que acreditavam que essas terras deveriam pertencer ao estado do Paraná ou do Rio grande do Sul. FLORES e SERPA enumeram as principais causas da colonização do Oeste catarinense bem como os motivos para a

${ }^{1}$ A viagem do chefe de estado Adolfo Konder ao oeste catarinense aconteceu no ano de 1929 (FLORES e SERPA, 2005).
${ }^{2} \mathrm{O}$ retalhamento da terra acontecia pois os pais dividiam as terras entre o filhos homens quando esses constituíam uma nova família. viagem de Adolfo Konder ${ }^{1}$ a essa região:

... a questão da fronteira nacional com a Argentina e da construção da brasilidade; a premência da ocupação do Oeste catarinense como expansão do processo civilizador para o interior, não só do estado, como também do país; o empenho em debelar as causas da Guerra do Contestado, vencendo poderes locais, em torno dos quais gravitavam grupos conflitantes. [...] Impunham-se eliminar os vazios demográficos e fazer com que as fronteiras econômicas, geográficas e culturais coincidissem com as fronteiras políticas. (FLORES e SERPA (2005 p. 130)

Outro fator que teria contribuído para a ocupação do oeste de Santa Catarina, especialmente por migrantes do Rio Grande do Sul descendentes de europeus, foi o esgotamento do solo gaúcho bem como o retalhamento da terra ${ }^{2}$ que dificultou o sustento das famílias numerosas que vieram para o oeste catarinense em 
busca de terras férteis "cheias de mato, terra boa". (RENK, 2000 e WERLANG, 2006).

Em 1919, a empresa Chapecó-Pepery Ltda, adquiriu toda a área de terras entre os rios Chapecó e Peperi. (HEINEN, 1997, p.250). Em viagem realizada pelos sócios da empresa, descendo o rio Uruguai, escolheu-se uma vargem abaixo do rio Antas para iniciar a colonização local de Porto Feliz, atual Mondaí Para colonizar a região, vieram principalmente os descendentes de alemães e italianos do Rio Grande do Sul. Antes de esses agricultores chegarem a Santa Catarina, eles ou seus ancestrais haviam migrado da Alemanha, em busca de condições para uma vida melhor.

Os agricultores que imigraram ao RS realizavam suas práticas agrícolas e associativas nos moldes aprendidos de seus ancestrais. $\mathrm{O}$ solo, flora e as culturas praticadas na Europa não encontravam similaridade no Brasil. $\mathrm{O}$ uso intensivo do solo, o emprego de técnicas de plantio, contribuíram para degradação do solo. Os colonizadores, em busca de melhores terras e de terras em maior extensão, migraram do Rio Grande do Sul para o oeste de Santa Catarina.

Para esses agricultores que migraram do RS para Santa Catarina, a busca e o acesso à terra é característica dos camponeses, de sua identidade e do trabalho familiar numa economia corporada (RENK, 2000 p. 18). Os colonos demandavam terra para seus filhos e netos para que pudessem constituir e sustentar suas famílias, que faz parte do processo de reprodução social camponesa. Shanin (2005) afirma que as características determinantes do campesinato parecem repousar na natureza e na dinâmica do estabelecimento rural familiar, enquanto unidade básica de produção e meio de vida social. Percebe-se então a necessidade do pai em proporcionar ao filho condições de ter a sua propriedade quando constituísse uma nova família.

O cultivo predador, como um importante fator que leva a migração de colonos, é apontado por Werle (2005). O autor destaca que a terra vista apenas como "objeto de exploração"; (os métodos de trabalho considerados problemáticos como as queimadas, o desmatamento indiscriminado, a ausência de adubação e rotação de cultura) fez com que o solo fosse degradado, fazendo com que o colono fosse em busca de novas terras. Embora Werle aponte problemas ambientais, estudiosos do campesinato, a exemplo de Woortmann e Woortmann, lembram que para os camponeses a 
terra é mais que objeto mercantil. Reveste-se de qualidades que poderíamos atribuir como o caráter moral da propriedade.

Renk (2000) escreve que os colonos tinham diferentes estilos de vida. Os colonizadores italianos tinham maior grau de homogeneidade, a maioria era católica. Entre os alemães as diferenças eram mais salientes, em razão das diferentes regiões de procedência da Europa, além disso, havia as diferenças religiosas; católicos e evangélicos. Aborda também a heterogeneidade no grau de escolarização e a clivagem econômica.

Devido à ausência do Estado no oeste catarinense, as igrejas exerciam uma forte influência na organização social e produtiva das colônias. As colonizadoras dispunham de terras, com possibilidade de venda em parcelamento. No entanto, as condições encontradas nas novas colônias eram precárias. Careciam de recursos médicos, escolares, e sofreram com o isolamento. $\mathrm{O}$ estado manteve-se distante, suas ações não atingiam região, salvo a cobrança de taxas e impostos. Em face da ausência e omissão do estado, a igreja passou a exercer um papel fundamental na formação ideológica dos agricultores. Eidt (2006) afirma que a colônia de Porto Novo foi pautada no tripé Deus, família e propriedade. Koelln (1980) também escreve sobre a influência da igreja luterana na organização das famílias da colônia de Porto Feliz.

A migração para as colônias de Porto Novo e Porto Feliz termina na década de 1960, quando se inicia um novo ciclo: os colonos desta região se deslocam ao sudoeste do Paraná e outras áreas, já que a terra na região se torna escassa e já á grandes problemas com o esgotamento do solo. Tal processo, de emigração dessas colônias acentua-se nas décadas seguintes, como uma das conseqüências da modernização da agricultura.

Nas colônias sulistas, em razão do processo de povoamento disperso, seguindo os cursos de água ou estradas, os moradores organizavam-se nas chamadas linhas ou comunidades e contavam com pequenos núcleos aglutinados, não necessariamente geográfica, mas socialmente, em torno de equipamentos comunitários, sejam capelas ou escolas. Nessas comunidades o representante da igreja (Padre para os católicos e o Pastor para os evangélicos) era visto como um líder junto aos camponeses. Esse fator favoreceu a reconstrução do modo cultural na região oeste catarinense, especialmente em relação à religiosidade e à língua alemã. 
As linhas coloniais, às vezes também chamadas de picadas, eram linhas ou estradas pelas quais seguia a colonização. Abria-se uma estrada na floresta, geralmente ao longo do leito de pequenos rios, a partir da qual se mediam os lotes das famílias. Nestas linhas se fundavam as comunidades, que eram grupos de moradores, com suas propriedades rurais localizadas próximas umas das outras, que construíam uma igreja, escola e salão de festas (HANN 2005, p. 31 e 32$)$.

As linhas coloniais eram divididas de tal forma que todas tivessem acesso à água e a estrada, o que foi chamado de "espinha de peixe". A maioria dos colonizadores fez suas instalações (casa, chiqueiros, estrebarias) próximas aos rios, para facilitar o acesso à água. Essa ocupação as margens dos rios contribuiu para a destruição da mata ciliar, acentuou o processo erosivo do solo e contribuiu para o assoreamento dos rios.

Observa-se que os métodos de trabalho, principalmente aqueles que agrediam o solo e a água, eram preocupação nas primeiras décadas da colonização, no entanto, os modos de produção mudaram na perspectiva de um aumento de produção e não numa perspectiva de conservação ambiental.

Por outro lado, Hann (2005 p. 33) relata notícia publicada no St. Paulusblatt ${ }^{3}$ de 1928, onde fica explicito que os colonizadores teriam o compromisso de desmatar:

Atenção! Compradores de terras de "Porto Novo". Todo um grupo de compradores de lotes de nossa colônia que fizeram suas compras a (sic) dois anos, não estão cumprindo suas clausulas contratuais de desmatar a floresta (grifo meu), construir e morar em suas terras. Para o interesse do desenvolvimento de nossa colonização, o não cumprimento desses termo contratual não pode ser adiado por muito tempo. Por isso quem não cumprir suas obrigações contratuais até a primavera, isto é, até final de setembro, perde seus direitos da colônia comprada e a terra estará a disposição da administração da colônia.

Por contrato a exploração da madeira ficaria a cargo da Volksverein (Sociedade União Popular - SUP) ${ }^{4}$, especialmente as espécies com valor comercial. Junglut (2005, p. 82) escreve que nem mesmo o mato tinha valor, as espécies que tinham valor comercial como: cedro, louro e cabriúva, eram de direito da Volksverein.
${ }^{3}$ Periódico publicado e distribuído pela Igreja Católica.

${ }^{4}$ Associação responsável pela colonização de Itapiranga. 
Apesar das exigências da colonizadora para a retirada da mata, para os colonos o mato era algo a ser removido á medida das necessidades de reprodução social. Woortmann (1997) referindose aos colonos do Rio Grande do Sul, afirma que se procurava fazer um rodízio de terras produzindo um movimento cíclico em que a natureza se tornava espaço de lavoura para voltar a ser natureza, era necessário deixar a terra "descansar". A presença da mata para os teuto-brasileiros tinha um significado de previsão, no sentido de assegurar recursos para a geração futura, "colono que se preza, para ser respeitado pelos demais, deve ter uma área de mata, símbolo de uma boa administração" (Woortmann, 1997 p. 28). Agricultores entrevistados, descreveram que seus pais e avós também respeitavam o pousio, ou seja, procuravam deixar a terra descansar.

A região, antes da colonização, era coberta por uma densa mata: Floresta Estacional Decidual e Floresta Ombrófila Mista e ambas ocupações florestais caracterizavam-se por madeiras de grande valor econômico como: Pinheiro-brasileiro, Grápia, Imbuia, Cedro, Canafistula, Louro-pardo, Guajuvira, entre outros (BAVARESCO, 2005). A fertilidade do solo e a existência de uma floresta constituída de madeiras de lei e nobres contribuíram de forma significativa para a colonização da região. Belani (1996), afirma que a exploração das matas e a indústria madeireira tornaram-se pilares da economia oestina. A bibliografia salienta a exploração da madeira pela Volksverein (JUNGBLUT, 2005). Não se têm dados a respeito da empresa colonizadora Pepery Guaçu.

Bavaresco (2005, p. 73) conta que as empresas colonizadoras exploravam a madeira mais nobre e só depois vendiam as terras aos colonos, propiciando o desenvolvimento da indústria madeireira na região. Acrescenta que com a extração da madeira e a derrubada da mata para as lavouras de subsistência, houve uma grande concentração de madeireiras e serrarias que aproveitavam a madeira disponível, o baixo preço da madeira era compensado pela grande quantidade e variedade de espécies comercializadas, provocando a atividade de derrubada e comercialização.

Essa madeira era exportada para a Argentina. O transporte era feito através do rio Uruguai, faziam-se as balsas, e em épocas de cheias as mesmas eram conduzidas pelos balseiros até São Borja e lá eram exportadas. 
O relevo da região oeste de Santa Catarina caracterizase pelo Planalto Dissecado rio Iguaçu/rio Uruguai, tendo uma superfície muito irregular. Predominam os solos Cambissolo, Cambissolo Húmico que são solos de menor profundidade e em desenvolvimento (BAVARESCO, 2005, p.85)

Essas características do relevo e do solo, aliadas a prática da coivara $^{5}$ e ao desmatamento, contribuíram para a transformação da paisagem e agravaram os problemas ambientais sofridos na região, especialmente o processo de erosão do solo, assoreamento dos rios e esgotamento do solo, pondo em risco os recursos ambientais e a produção agrícola.

O desmatamento ao longo dos rios e nos topos dos morros, além da caça indiscriminada contribuíram para a poluição das águas superficiais e também para a perda de grande parte da biodiversidade da região.

No inicio da colonização, para a construção das propriedades, das comunidades e para a produção agrícola, transformou-se o meio natural usufruindo-se de seus recursos para o sustento. Testa et alii (1996) afirmam que os recursos naturais da região constituíram-se em um dos pilares do processo de colonização em pequenas propriedades. Dessa forma temos os ciclos econômicos extrativistas da exploração da madeira, erva-mate e em menor grau de gado bovino extensivo. Após a exploração principalmente da madeira, a economia passou a se basear na produção agrícola onde a família organizava o processo produtivo e o trabalho. O mesmo autor aborda que, historicamente, a produção de excedentes serviu de base para o surgimento das agroindústrias a partir da década de 1960. Acrescenta ainda que a maior parte dos estabelecimentos tinha a suinocultura como uma relevante fonte de renda e que grande parte da produção de grãos era destinada a suinocultura, diz que o sistema de produção regional poderia ser denominado de policultura subordinada à suinocultura.

A difícil situação de infra-estrutura e o tamanho do lote colonial, que tinha em média 24 hectares propiciaram aos colonos apenas desenvolverem uma produção para subsistência (BAVARESCO, 2005, p.89). O sentido de subsistência explicado inicialmente pelo desenvolvimento da policultura, a família procurava plantar espécies vegetais essenciais para a alimentação da família, caso houvesse algum excedente esse era comercializado num armazém local, essa comercialização se dava em forma de troca, possibilitando ao colono a obtenção de produtos
5 A grande maioria dos colonos, após a retirada da mata praticavam a coivara, ou seja, queimavam a capoeira e com isso eliminavam grande parte da micro vida do solo. Neumann nomeia essa prática de Raubbe. (www.upf.br/ppgh/download/RosaneMarciaNeumann.prn. pdf acessado em fevereiro de 2009). 
manufaturados ou de impossível produção na sua colônia, tais como: sal, querosene, tecidos e ferragens. Eidt faz menção á produção de subsistência desenvolvida pelos colonos:

Os recursos naturais da região viabilizaram um modelo de desenvolvimento econômico de reduzida orientação para o mercado. A existência de mata nativa e a boa fertilidade natural do solo propiciaram ao migrante uma relativa autonomia e auto-suficiência, dentro dos limites estabelecidos pelos mentores da colonização. As famílias extraiam seu sustento exclusivamente da terra, com primitivismo justificável, em face ao isolamento das colônias, das terras íngremes e da necessidade de ocupar a mão de obra familiar. (EIDT, 1999, p. 64).

Em relação ao desenvolvimento da pecuária, a criação de suínos, aves e gado de leite eram para o consumo próprio. Apenas a banha suína era comercializada. Esses animais eram criados livremente na propriedade, a alimentação desses animais era baseada em mandioca, pasto e milho.

Percebia-se um total descaso por parte do Estado em relação ao oeste catarinense, Renk (2006), escreve que os núcleos coloniais, as margens do rio Uruguai, só geograficamente estavam inseridos no estado de Santa Catarina. As relações comerciais, bem como os vínculos com a Igreja Evangélica Luterana, eram tidas com o Rio Grande do Sul, cujas orientações emanavam deste estado. A mesma autora afirma que no litoral catarinense havia um imaginário sobre a região oeste enquanto terra de barbárie, inóspita e paraíso da criminalidade.

A economia da região oeste, no final da década de 1950, era pouco integrada aos mercados nacional e internacional. A madeira, a banha e o fumo constituíam-se nas únicas fontes de renda da população. Hahn (2005), afirma que a criação do suíno tipo banha respondia por aproximadamente $73 \%$ da renda dos agricultores.

Era necessário reverter esse baixo índice de desenvolvimento econômico da região oeste catarinense, já que, vivia-se em um período da história nacional que era necessário crescer, produzir, superar obstáculos que pudessem por em risco o progresso do Brasil, é nesse contexto que surge a extensão rural, para instituir um modo de produção que reverta esse quadro de baixa produtividade. 
A ocupação do território e a transformação da paisagem da região pesquisada se deu a partir do campesinato, onde priorizavase a sobrevivência da família. A organização comunitária e a "extensão" rural era feita pelo clero, foram substituídos por novos conhecimentos que modernizassem a produção agrícola, conhecimentos difundidos por um serviço público de extensão rural.

A Extensão Rural no estado de Santa Catarina iniciou suas atividades no ano de 1957, com os mesmos objetivos e princípios que de âmbito nacional; a formação educacional dos agricultores que proporcionasse conhecimentos técnicos para desenvolver um modo de produção moderno. Seiffert (1990, p.68) afirma que o plano postulava, através de campanhas educacionais, conduzir os agricultores a se tornarem autônomos o que possibilitaria a execução de empreendimentos, com o objetivo de aumentar os lucros, dessa forma a produção agrícola se tornaria mais capitalista. Governantes afirmavam que a renovação da economia agrícola e pastoril repousava no abandono dos processos de rotina e na adoção de métodos, sistemas e recursos modernos, que possibilitassem maiores rendimentos com menor parcela de esforço; só assim se obteria melhor aproveitamento das energias humanas. No entanto para que houvesse um aumento da produtividade era necessário que ações fossem voltadas para a conservação do solo.

A preocupação em relação a fertilidade do solo na região oeste catarinense é antiga. Um dos problemas que mais contribuem para essa a perda da produtividade na agricultura é a erosão do solo. $\mathrm{O}$ solo da região caracteriza-se por ser raso e pedregoso, isso aliado ao desmatamento e ao fato da topografia da região ser muito acidentada, contribuiu para um processo acentuado de erosão do solo. Testa et alii (1996) afirma que devido a essas características o solo da região é impróprio para as culturas anuais, em função disso a erosão do solo é um problema ambiental que inquieta os agricultores desde a década de 1970.

Em relação á erosão do solo, a extensão rural através dos clubes $4 s^{6}$, tivemos várias iniciativas, com o desenvolvimento de práticas para conter a erosão como: taipas de pedra, as curvas de nível com o plantio de cana de açúcar, capim falares, terraços, patamares e o cultivo mínimo ou plantio direto e especialmente o reflorestamento de espécies exóticas que poderiam aumentar a renda familiar.
${ }^{6}$ Os clubes 4 s era uma das estratégias utilizadas pela extensão rural para disseminar novos conhecimentos em relação a produção agrícola e pecuária objetivando o aumento da produção e do lucro do pequeno agricultor, poderíamos afirmar que é a inserção do capitalismo no campo. Entre as ações desse clube temos o incentivo a plantação de eucaliptos como alternativa econômica e para a contenção da erosão do solo. 


\section{O Reflorestamento}

A extração de madeira na região extremo-oeste de Santa Catarina se acentuou com a chegada das empresas colonizadoras, a retirada das matas iniciou nas margens dos rios e à medida em que expandiam a ocupação, retiravam as madeiras encontradas nessas terras. Cancian (apud CARVALHO e NODARI, 2007, p. 274) faz uma descrição da derrubada da mata pelos agricultores no Paraná, descrição essa que se assemelha a atividade extrativa da mata ocorrida na região oeste de Santa Catarina: O primeiro ato do cultivador não é lavrar a terra, mas desflorestar. Começa-se pela roçada, isto é, a limpeza à foice da subfloresta que se efetua em maio; deixa-se durante algumas semanas, de maneira a cobrir o solo com um leito de plantas bem secas, o facho; depois vem a derrubada, que consiste em por abaixo as árvores.

Nos anos iniciais da colonização as terras eram avaliadas pela quantia de mata que ainda dispunha, aquela com pouca floresta, ou seja, a limpa custava mais do que a área com mata, o que incentivou a retiradas das florestas (CARVALHO e NODARI, 2007 , p. 275). As mesmas autoras ainda salientam que manter a terra limpa, sem mato era uma forma que ajudava a confirmar a posse ou a propriedade.

Segundo as autoras, a floresta era vista pelos agricultores como "nada", era um obstáculo a ser superado, um nada, um marco zero a partir do qual se constrói a história da realização de se tornar proprietário rural.

O desmatamento aliado a topografia acidentada da região foi outro grande causador do processo erosivo do solo. Entre as atividades de conservação do solo inseriu-se o reflorestamento. Tal iniciativa foi marcante, pois se percebe na fala de todos os entrevistados a lembrança relacionada ao reflorestamento.

Através do trabalho realizado pelos clubes $4 s$ é que se iniciou o plantio de árvores exóticas na região principalmente o eucalipto (Eucaliptus spp) e a uva do Japão (Hovenia dulcis), espécies que se adaptaram à região e muito bem se desenvolveram. Plantar eucaliptos era considerado bonito, pois eram homogêneos e plantados em carreira, esse plantio não se assemelhava a floresta encontrada na época da colonização. $O$ plantio de eucaliptos também obteve sucesso, pois eram plantados em áreas que não fossem adequadas para o cultivo, com alta altitude, essas deveriam ser utilizados para o reflorestamento, mas um reflorestamento que pudesse proporcionar lucros a médio prazo, para isso era necessário 
plantar uma espécie de fácil cultivo e rápido crescimento. $\mathrm{O}$ exsócio do Clube 4-S C.M. conta sobre o reflorestamento, cita as áreas de terra e as espécies de árvores escolhidas para o plantio:

Me lembro do reflorestamento, das mudas que fizemos. Em casa, criei mudas e depois até ajudei a plantar, era plantadas em terras com muita pedra, muito morro, aquelas que não tinha utilidade para o plantio, essas eram para o reflorestamento. Era na verdade era um florestamento, plantava-se muito uva do Japão que na época por aqui não tinha ainda, e eucalipto. Se hoje esta quase tudo cheio desta árvore, fomos nos que praticamente plantamos na época do clube $4 \mathrm{~s}$, plantamos nos morros por ai e hoje a uva do Japão praticamente virou um inço, ela cresce muito fácil (C. M.).

C.M. diz ainda que não se cogitava a idéia de que as espécies de árvores exóticas pudessem trazer conseqüências danosas ao ambiente. Afirma que na época tinha-se a cultura de derrubar muito mato, pois todo o ano pensava-se que tinha que ter "terra nova", fazia parte da cultura da família a rotação de terras. Afirma que talvez o cultivo de eucalipto e de uva do Japão não tenha sido a melhor opção, mas que dessa forma iniciou-se uma consciência da necessidade da preservação e do replantio de árvores.

$\mathrm{Na}$ fala do ex-sócio do Clube 4s, I.K. observa-se como o cultivo dessas novas espécies foi marcante:

Mas o que mais chamou a atenção era a questão do reflorestamento foi em 83 ou 84, não lembro ao certo, daí a questão do reflorestamento foi bastante grande, daí foi formados grupinhos para reflorestar. Produziam as mudas na própria comunidade e depois distribuíam para os outros replantar. Era mais uva japonesa e principalmente eucalipto. As primeiras sementes quem trouxe foi o extensionista da ACARESC e depois os sócios dos clubes $4 \mathrm{~s}$ foram buscar em outras comunidades. Porque hoje temos muitos tipos de eucalipto na região, tudo que veio da época dos $4 \mathrm{~s}$.

A plantação de árvores exóticas é questionável, pesquisadores asseguram que tais espécies põem em risco a biodiversidade regional, tal ameaça agrava-se quando as plantas exóticas ocupam o espaço das espécies nativas. Primack et alii (2001) acrescentam ainda que a introdução de espécies exóticas podem deslocar as espécies nativas através de competição por limitação dos recursos, quando essas espécies se adaptam ao novo habitat, pondo em risco a biodiversidade local. 
No Guia Florestal para Clubes 4s, distribuído pela ACARESC, orientava-se o plantio de árvores exóticas de forma descritiva e também ilustrativa. O uso de fungicidas para o combate às doenças nos viveiros, bem como na plantação das árvores também era sugerido, orienta-se o tipo de veneno que deve ser utilizado, bem como a quantia. Também á orientações quanto o espaçamento da cova na qual irá se plantar a muda e também o espaçamento que deve ter entre as mudas. Na capa do Guia, as áreas de terra impróprias para a agricultura são sugeridas enquanto ideais para o reflorestamento, não observou-se maiores preocupações com o reflorestamento nas margens de rios ou fontes de água.

A partir da pesquisa realizada o que se percebe é que a idéia principal era plantar eucalipto como uma alternativa econômica, já que essa planta adequava-se as condições naturais da região e se desenvolvia de maneira rápida.

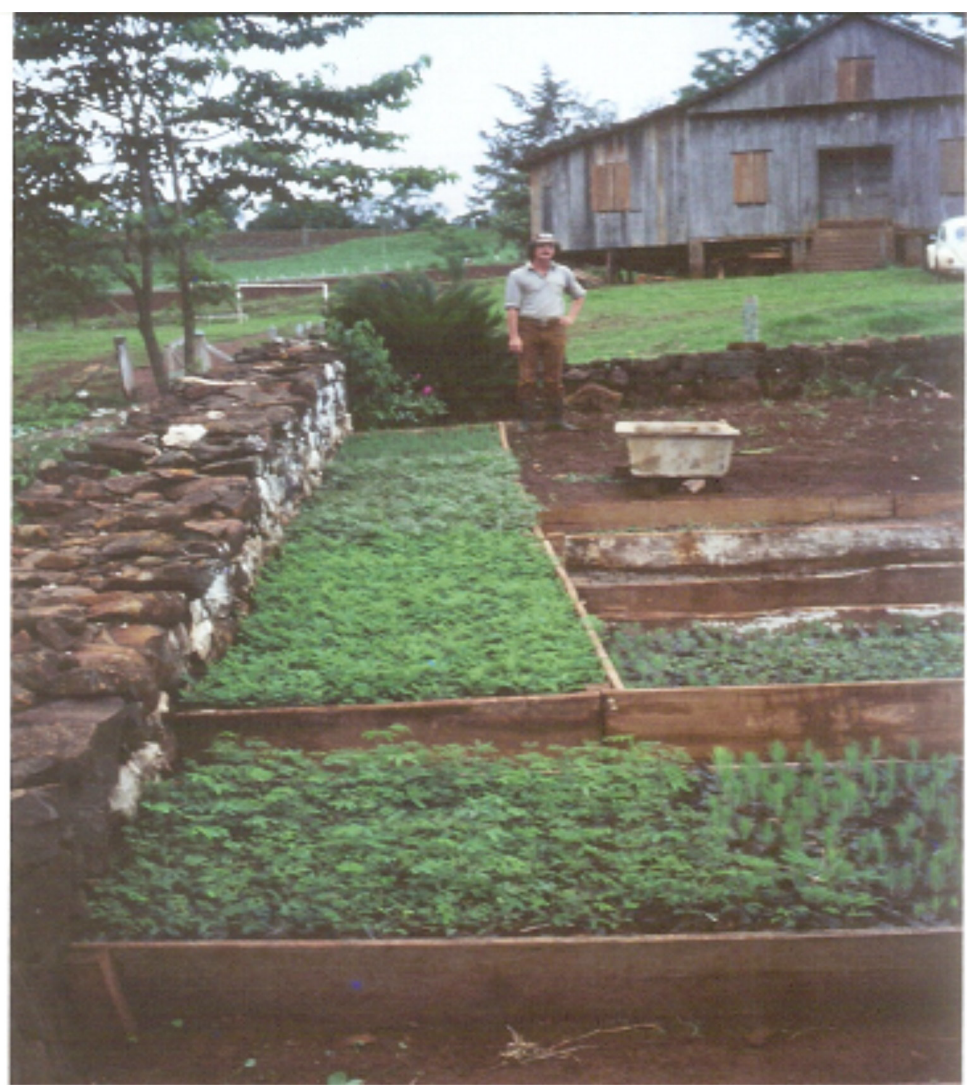

Figura n 04.8 Viveiro de Mudas 4s

Fonte: Acervo pessoal de Euclides Faé. 
Essa visão é recorrente até hoje, o que se observa nos municípios pesquisados (Itapiranga e Mondaí) é um aumento da área cultivada com eucalipto. Atualmente as indústrias moveleiras e as agroindústrias regionais incentivam tal produção.

\section{Vantagens e Desvantagens do Plantio de Eucaliptos}

O plantio de eucaliptos, que iniciou na região por volta da década de 1970 e 1980, com o trabalho dos clubes 4s, vem se intensificando nos últimos anos. Nos municípios de Mondai e Itapiranga esse plantio tem sido visto como uma alternativa econômica para a agricultura familiar. Outro fator que contribuiu para o aumento dessa cultura foi a necessidade das indústrias se adequarem a nova legislação.

À medida que se intensifica a exploração da madeira, a questão do desmatamento vem a tona. Cabral e Cesco (2008, pág. 41) afirmam que leis e decretos são instaurados para regularizar o corte, transporte, exportação e reflorestamento. Pela obrigatoriedade legal de as empresas consumidoras serem também produtoras de matéria prima florestal, as indústrias moveleiras e as agroindústrias locais passaram a adquirir extensas áreas de terra para o florestamento de eucalipto.

Defensores do plantio de eucalipto asseguram que além de ser uma alternativa econômica, essas plantações podem mitigar os efeitos da mudança climática ao agirem como "sumidouros de carbono" (CARRERE, 2008).

Analisando estudos sobre os efeitos da plantação de eucaliptos de Céspedes, pesquisador da Faculdade de Ciências do Uruguai, Carrere (2008) afirma que tal cultura tem efeitos negativos no solo da Pradaria, ecossistema típico da Argentina, Uruguai e sul do Brasil. Em tal estudo, Céspedes diz que as monoculturas de eucalipto provocam uma importante perda de matéria orgânica e conseqüentemente aumenta a acidez do solo, como conseqüência determinadas espécies de plantas nativas passam a não ter condições de se desenvolver. Devido a essas mudanças físico-químicas do solo, os microorganismos seriam ainda mais prejudicados por serem sensíveis à essas transformações (CARRERE, 2008).

O mesmo autor aborda ainda que o ambiente mais ácido contribui para a proliferação de fungos que geram um emaranhado de micélios sobre a terra provocando a impermeabilização do solo, impedindo a penetração de água à camadas mais profundas. 
Outra conseqüência negativa da monocultura do eucalipto é o desgaste do solo. Céspedes (apud CARRERE, 2008) assegura que o solo utilizados por atividades agrícolas deveriam ser abandonados para serem recolonizado por espécies nativas. No entanto, pela estrutura fundiária e pela perspectiva de aumento da renda familiar, cultiva-se arvores exóticas que tenham um rápido crescimento e sejam de fácil comercialização, nesse caso o eucalipto.

A plantação de arvores com fins comerciais, segundo Cabral e Cesco (2008), toma forma com a sensível diminuição da mata nativa, Leão (apud CABRAL E CESCO, 2008) diz que o Brasil no final da década de 1950 era considerado o país com as mais extensas plantações de eucalipto do mundo e que em anos posteriores esse cultivo só aumentou, afirma ainda que tal cultivo foi justificado por considerar-se uma exploração madeireira autosustentável, onde diminuiria-se a exploração da mata nativa já bastante escassa.

Percebe-se uma contradição nas pesquisas em relação a plantação de eucaliptos, à pesquisas que abordam que a plantação de eucaliptos é uma alternativa econômica para a agricultura familiar, outros dizem que esse plantio pode diminuir a exploração da mata nativa.

Ecólogos afirmam que o plantio de eucalipto acarreta em graves conseqüências ao ambiente, afirmam que á um grande desgaste do solo, uma perda da biodiversidade local, problemas relacionados com a poluição da água e do solo por agrotóxicos.

Particularmente acredito que a monocultura de eucalipto provoca graves conseqüências ao ambiente e que os benefícios econômicos de tal cultivo não são suficientes se contarmos os malefícios ao ambiente de tal produção. Os rumos de tal produção nos municípios de Mondai e Itapiranga são preocupantes, pois o plantio de eucaliptos não é mais visto como uma cultura alternativa para a agricultura familiar. $\mathrm{O}$ que se observa é que extensas áreas são adquiridas por representantes das indústrias, especialmente a moveleira e a agroindústria, e se pratica a monocultura do eucalipto.

O que se observa é um movimento inverso ao do deflorestamento. Naquele momento, mesmo que realizado de forma inadequada, fazia parte da prática camponesa de extração de florestas para o plantio, tendo em mente a reprodução social camponesa. 
O plantio do Eucaliptus spp significa alteração na paisagem rural. De um lado, observa-se a incorporação de pequenas propriedades, aglutinadas, e destinadas à monocultura do eucalipto, com vistas ao valor econômico que possa representar em alguns anos. Torna-se uma estratégia, não de reprodução social camponesa, mas de empresários que procuram assegurar o futuro com uma mercadoria que ganha valor nas indústrias locais. Ou seja, reflorestamento com eucalipto significa a lógica oposta a do mundo camponês. Vale-se de suas terras já fragmentadas, utiliza-se de planta exótica que poderá ser rentável em período relativamente curto, e modificar a paisagem do ponto de vista estético, físico e social. Provavelmente, as futuras gerações conhecerão um inferno verde, bem diferente das florestas nativas.

\section{Referências}

BAVARESCO, Paulo Ricardo. Ciclos Econômicos Regionais: empobrecimento no Extremo Oeste Catarinense. Argos: Chapecó, 2005.

BELLANI, Eli, M. Madeiras, Balsas e Balseiros no Rio Uruguai: o processo de colonização do velho Município de Chapecó (1917/1950) (Dissertação de Mestrado). Florianópolis: UFSC, 1991.

CARVALHO, Ely Bergo de; NODARI, Eunice Sueli. A Percepção na Transformação da Paisagem: Os agricultores no Desflorestamento de Engenheiro Beltrão - Paraná, 1948-1970. História, v.26, no2, p. 269287. São Paulo, 2007.

CASTANHEIRA, Marco Antonio Silveira. Responsabilidade da Juventude Rural na Preservação do Meio Ambiente. I Seminário Regional de Juventude Rural 4s. São Miguel do Oeste, 1981.

EIDT, Paulino. Porto Novo: da escola paroquial ao projeto de nucleação, uma indentidade em crise. Editora UNIJUI. Ijuí, 1999.

Projeto Porto Novo: Fé, Altruísmo e Contradições dos Alemães no Oeste de Santa Catarina. (Tese de Doutorado). São Paulo: PUC, 2006.

FURTADO FILHO, Dorvalino; SILVA, Francisco Cunha; FRANCO Multion, Homero. Gotas de Suor uma trajetória de 40 anos. Epagri. Florianópolis, 1996. 
FLORES, Maria Bernadete Ramos Flores; SERPA, Élio Cantalício. A Hermenêutica do Vazio: Fronteira, Região e Brasilidade na Viagem do Governador ao Oeste de Santa Catarina. CEOM. A Viagem de 1929, Oeste de Santa Catarina. Chapecó: Argos. Chapecó, 2005

GERTZ, René E. Imprensa de Língua Alemã e Meio Ambiente no Rio Grande do SUL. In: DREHER, M., MARLIN, N. et alii (org). Imigração e Imprensa. Porto Alegre, EST, 2004.

HAHN, Mauro. Capital Social e Estratégias de Desenvolvimento Econômico da microrregião de Itapiranga (SC). (Dissertação de Mestrado): Florianópolis: UFSC, 2005.

HEINEN, Luiz. Colonização e Desenvolvimento do Oeste de Santa Catarina. Aspectos Sócio-Político-Econômicos e Religiosos. Joaçaba: Editora UNOESC, 1997.

Livro de Atas do Clube 4s Sentinela do Uruguai de Vila Catres, Mondai.

KOELLN, Arno. Porto Feliz. A História de uma Colonização às Margens do Rio Uruguai. Mondaí: Coordenadoria Municipal de Ensino, 1980.

KREUTZ, Lúcio. O Professor Paroquial: Magistério e Imigração Alemã. Porto Alegre: UFRGS, 1991.

NEUMANN, Rosane Márcia. Uma Colônia para Imigrantes Alemães: Neu Wurttemberg. www.upf.br/ppgh/download/ RosaneMarciaNeumann.prn.pdf. Acessado em Fevereiro de 2009.

OLINGER, Glauco. Ascensão e Decadência da extensão rural no Brasil. Epagri. Florianópolis, 1996.

RAMBO, Lorival Inácio. Um Outro Olhar Sobre a Colonização: A Relação Homem/Natureza. (Dissertação de Mestrado). Chapecó: Unochapecó, 2007.

RENK, Arlene. Sociodicéia às Avessas. Chapecó: Grifos. Chapecó, 2000 .

A Luta da Erva. Chapecó: Argos, 2006.

SEIFERT, Raquel Quadros. Extensão Rural em Santa Catarina: Impasses Políticos-Pedagógicos (1956 - 1985). 1990. (Dissertação de Mestrado). Florianópolis:UFSC, 1990. 
SHANIN, Teodor. A Definição de Camponês: Conceituações e

Desconceituações - o Velho e o Novo em uma Discussão Marxista. Revista Nera. Ano 08, n.07, p. 01-21. Presidente Prudente. Jul./Dez. 2005 .

SILVA, Claiton Marcio da Saber, Sentir, Servir e Saúde: A Construção do Novo Jovem Rural nos Clubes 4-s, SC (1970-1985). (Dissertação de Mestrado). Florianópolis: UFSC, 2002.

TESTA, Vilson Marcos et alii . O desenvolvimento sustentável do oeste catarinense: (proposta para discussão). Florianópolis: EPAGRI, 1996.

WERLANG, Alceu Antonio. Disputas e Ocupação do Espaço no Oeste Catarinense. Chapecó: Argos. 2006.

WERLE, André Carlos. Agricultura e Meio Ambiente em Congressos Católicos. II Congresso Sul Americano de História. Passo Fundo, 2005 .

WOORTMANN Ellen F.; WOORTMANN Klass. O Trabalho da Terra. Brasília: Editora UNB, 1997.

WOORTMANN, K. Com parente não se negoceia: o campesinato como ordem moral. In: Anuário Antropológico. Brasília/Fortaleza: Editora UNB/ Tempo Brasileiro: 1987.

Entrevista MAB - Pedro

\begin{abstract}
The colonization of the municipality of Mondaí, relied on farmers who migrated in search of lands, as a farmer social reproduction strategy. The testimonials and documents point out that there were practices of devastation of forests at the expense of the environment. Contemporaneously the opposite has been observed, an intensive reforestation, reaching diverse rural lines. However, this is the strategy of businessmen and professionals liberal in the planting eucalyptus trees as a strategy of social reproduction, as the wood can serve as a form of savings and income for the investor.
\end{abstract}

Key words: colonization, deforestation, rural extension, planting of eucalyptus trees. 
